\title{
Escapando das armadilhas dos métodos
}

\section{Escaping the traps of methods}

\author{
Ana Paula Alves Ribeiro \\ Pesquisadora no Núcleo de Pesquisa das Violências/ \\ Instituto de Medicina Social/Universidade do Estado do Rio de Janeiro \\ anapalvesribeiro@gmail.com
}

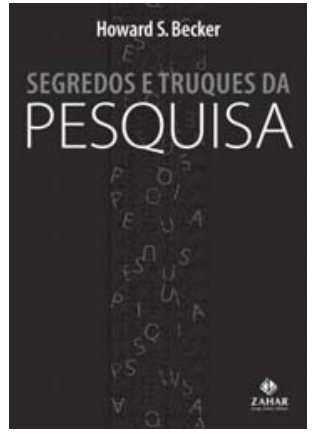

Becker, Howard S. Segredos e truques da pesquisa. Rio de Janeiro: Jorge Zahar, 2007. 296 p. (Coleção Nova Biblioteca de Ciências Sociais).
$\mathrm{E}$ m momento no qual a interdisciplinaridade está em evidência e a prática da pesquisa se torna intenso diálogo entre os vários métodos oferecidos pelas mais diversas escolas, Segredos e truques da pesquisa vem corroborar a importância dos instrumentos teóricos à disposição dos cientistas sociais.

Escrito por Howard S. Becker, professor em São Francisco, Califórnia, lançado em 1998 nos Estados Unidos e publicado no Brasil por Jorge Zahar Editor, o livro apresenta linguagem clara, acessível ao público não só das ciências sociais, mas também de áreas afins, como saúde. Alguns dos livros anteriores de Becker aqui editados - Uma teoria da ação coletiva (1977), Métodos de pesquisa em ciências sociais (1994) e Outsiders (1966) - são bastante utilizados em cursos de graduação e pós-graduação, tendo-se tornado referência para vários autores das ciências sociais brasileiras. A familiaridade do autor com outras culturas, como a nossa, por exemplo, e com

outras áreas - música, etnomusicologia, matemática e neurologia são algumas delas - nos faz pensar além de nosso próprio universo de análise.

Segredos e truques da pesquisa é livro generoso, pois Becker o transforma em longo diálogo com seus pares e sua linhagem. Seus métodos e técnicas de pesquisa não são apenas os seus; incluem os de seus professores, dos professores de seus professores, de seus colegas e alunos. Trata-se também do resultado de pesquisas realizadas ao longo de sua carreira, da relação estabelecida com seus entrevistados e do compromisso com seus objetos de pesquisa.

O propósito declarado do livro é "ajudar as pessoas a compreenderem como se faz o trabalho cotidiano de pesquisa em ciências sociais, como lidar com os problemas que incomodam estudantes e jovens pesquisadores quando se ocupam de aprender um ofício profissional estranho: pensar sobre os dados que colhem, escolher os lugares aonde vão colher seus dados e as pessoas que observam ou entrevistam" (p.7). A tarefa é difícil, mas Becker se propõe a fazê-la e faz bem. Ao estabelecer a linha narrativa na primeira pessoa, trazendo exemplos de seu cotidiano profissional, (re)apresentando-nos autores, ele nos aproxima de seus pares de ambos os domínios, teoria e metodologia, o que os torna nossos pares (e parceiros) também. 
O cuidado em deixar o texto palatável demonstra a preocupação, aliás explicitada, de um mestre cuja bagagem comporta anos de sala de aula. O pertencimento a sua cultura não é condição sine qua non para compreender seus exemplos, representações e conceitos. As diferenças nacionais aqui são um problema na análise da pesquisa, mas não para o entendimento do texto. Questões relativas às diferentes realidades apresentadas são aplicáveis aos problemas de pesquisa de outros contextos. Vários dos casos trazidos, por exemplo, se referem às diferenças culturais na área da saúde, isto é, como a clínica médica ou a pesquisa nessa área podem ser influenciadas em grande parte pela questão cultural. Diferenças étnicas, locais de residência, idade, sexo, entre outras variáveis, fazem parte tanto da realidade americana como da nossa. Podemos, portanto, nos beneficiar de exemplos referentes a análises feitas em universo diferente do nosso - como problemas e obstáculos dos antropólogos americanos na pesquisa com população que, a rigor, é extremamente diferente da nossa - para pensar nosso próprio universo, ou objeto, ou referencial.

Seu primeiro capítulo, "Truques", também é maneira de introduzir um livro original sobre métodos de pesquisa, reconhecendo simultaneamente a importância de autores e pesquisas anteriores ou contemporâneas às suas e sobretudo acessíveis. Não se trata de manual com receita de pesquisa, mas de diálogo permanente com o leitor, o que ajuda a estabelecer caminhos alternativos para antigos problemas.

Cada seção do livro aborda uma convenção científica, o que permite, segundo o autor, estender o pensamento além da revisão da literatura.

No segundo capítulo, "Representações", a preocupação de Becker se encontra nas imagens que criamos de nossos objetos, antes de iniciar de fato a pesquisa. Ele trabalha com a ideia de que temos basicamente dois tipos de representações, as substantivas e as científicas. Nas representações substantivas, o senso comum, ou seja, nossa visão de mundo e as imagens que dele fazemos no dia-a-dia precisam ser trabalhadas cientificamente. Essas representações substantivas podem ser estereótipos, recobertos de certeza e arrogância, que não nos deixam criar, acolher ou pensar novas representações mais adequadas a nosso objeto. Quanto às representações científicas, referem-se às configurações conceituais e representações partilhadas pelo grupo profissional do qual fazemos parte, o dos cientistas sociais, armadilhas das quais nos livramos pela mera clareza de que essas questões existem, e nos livramos mais confortavelmente se estivermos munidos de truques para lidar com elas. O que pode parecer óbvio talvez não seja tão óbvio assim. Os truques indicados, como o da hipótese nula utilizado para formalizar nosso pensamento -, o de pensar a sociedade como máquina ou como organismo, e também aqueles decorrentes do diálogo com as narrativas construídas pelos entrevistados, ainda são extremamente úteis. Posto que trabalho com minha visão de mundo e com a visão de mundo de meu grupo profissional, estou razoavelmente apto a pensar o problema do meu objeto de pesquisa com a minha construção de estereótipos e juízos de valor cientificamente controlados.

Alguns casos trazidos por Becker são recorrentes em pesquisas qualitativas e se referem à substituição do 'por que' pelo 'como'. Perguntar a um entrevistado resistente como ele se envolveu com alguma atividade ilegal, por exemplo, permite-lhe mais liberdade de estruturar sua própria narrativa e, a nós, entender melhor a trajetória ou o processo que o levou a se envolver na atividade. Quando perguntamos 'por que' demonstramos de alguma forma 
nossos juízos de valor e estereótipos, podendo ficar subentendido, por exemplo, que o acusamos de se ter envolvido em tal atividade.

O que está em jogo nesse capítulo são nossas considerações, nossos dilemas e nossas dúvidas na estruturação do objeto de pesquisa. Como, então, ter clareza de que "não somos aquelas pessoas e não vivemos nas circunstâncias delas" (p.33) e manter, ao mesmo tempo, nossa autoridade de pesquisador (tentando controlar nossos estereótipos e imagens preestabelecidas sobre o outro)? Não é questão - como, aliás, as demais apresentadas no livro - de fácil resolução. Cada trajetória de pesquisador e cada pesquisa darão tom diferenciado ao caminho a seguir ou ao truque a empregar.

Isso também ocorre em relação à amostragem, abordada no terceiro capítulo e percebida pelo pesquisador a partir de seus objetivos e do que quer entender em seu trabalho. A amostragem perpassa tanto a pesquisa qualitativa quanto a quantitativa e a que mescla os dois tipos, e diz respeito à seleção dos casos a serem estudados dentro de determinado universo. Ela precisa ser necessariamente representativa e evitar tendências, mesmo quando não utiliza procedimentos estatísticos. As variáveis com as quais trabalhamos devem ter valor tanto na amostra como na população estudada. Os métodos qualitativos têm, nesse tipo de análise, uma grande interação com os métodos quantitativos, assim como uma relação profícua com nossas próprias representações. Com relação à amostragem, o raciocínio deve ser: se a descrição total não existe, então como fazer as escolhas do que deve entrar na pesquisa? Como determinar o que excluir? Os truques servirão para responder a parte dessas perguntas. São os mais diversos, mas podem ser resumidos a afastar certas generalizações e duvidar. Duvidar da hierarquia da credibilidade, duvidar de que nada acontece em nosso trabalho de campo, duvidar de que todo mundo sabe de tudo, assim como dos dados trazidos por terceiros, não coletados por nós, e assumir o risco e as deficiências de utilizar informações que não foram observadas diretamente para nossos propósitos.

"Conceitos", o quarto capítulo, recomenda pensar "como usar dados para criar idéias mais complexa que nos ajudarão a encontrar outros problemas que merecem ser estudados" (p.146) e apresenta alguns casos representativos da diversidade dos conceitos. Citado por Becker, Blumer observa que "não é possível haver ciência sem conceitos" (p.146). Eles são guias que nos ajudarão a olhar, procurar e reconhecer algo quando encontramos. É a partir dessa premissa que Becker apresenta sua maneira preferida de desenvolver conceitos, estabelecendo "diálogo contínuo com os dados empíricos". Alguns cientistas constroem modelos típicos ideais, outros podem desenvolver seus conceitos manipulando ideias básicas. O diálogo com os dados empíricos é profícuo, uma vez que cada caso trará uma surpresa ou um resultado diferenciado, dependendo da maneira como o diálogo foi estabelecido e o conceito, definido.

A partir de dados empíricos e dos resultados de pesquisas, Becker aponta como os conceitos podem ser construídos na forma de processo, e apresenta dois casos para ilustrar as afirmações de que os conceitos podem ser generalizações empíricas e são relacionais. No segmento "Generalizações empíricas" ele pergunta, a partir de pesquisa de Marisa Alicea sobre migrantes porto-riquenhos nos Estados Unidos, se pode definir o local de residência de uma pessoa: trata-se do lugar em que se recebe correspondência, dorme-se, se pode ser 
encontrado, guardam-se as roupas? A pergunta do censo de 1960 era ambígua com relação a esses aspectos. Alicea aponta que os migrantes viajam a Porto Rico com frequência e sempre voltam a Nova York ou Chicago. Isso significa, para a autora e para Becker, que a generalização pode ser verdadeira ou não, positiva ou não, já que boa parte das pessoas mantinha, na realidade, duas bases de residência entre as quais transitava com regularidade.

Os conceitos são relacionais, posto que inseridos nos diferentes contextos. Crianças negras e hispânicas são rotuladas com retardo fronteiriço durante a fase escolar, mas o retardo fronteiriço é superado quando esses alunos saem da escola.

Como, então, é possível trabalhar com uma variedade de fenômenos, com uma diversidade de casos, sem colher mais e mais dados? Em "Lógica", o quinto capítulo, Becker recomenda lidar com a massa de dados empíricos de forma a que o resultado aponte uma direção. A partir de métodos específicos das ciências sociais, ele discute a produção da "tabela de verdade", isto é, a "classificação cruzada de variáveis qualitativas". Os métodos escolhidos foram análise do espaço de propriedades (AEP), análise comparativa qualitativa (ACQ) e indução analítica (IA). O que eles têm em comum, e esse é um truque, é a tentativa de extrair categorias, ideias, independentemente de seu valor.

Como proposta de conclusão, "Coda" é uma forma poético-musical de se despedir dos leitores. Refere-se às conclusões em música e em poesia. Até o final, interdisciplinar - qualidade que nem opõe nem hierarquiza as ciências e ainda as traz como colaboradoras no processo de pesquisa acadêmica.

Frequente no livro é a sinalização de que o óbvio não é tão evidente e que o insistente refazer de perguntas pode trazer respostas não esperadas, o que é positivo para a pesquisa como um todo. Fica a impressão de que Segredos e truques, por não ser um manual, mas sim uma possibilidade de caminho a seguir, deixa margem para diversos tipos de leitura, dependendo da experiência profissional e do tipo de pesquisa em questão.

Ao dialogar com sua linhagem e seus pares, Howard Becker nos insere em prazerosa caça ao tesouro e nos faz um grande convite: abandonar nossas certezas, juízos e nossa própria fé, e embarcar numa oportunidade única de perceber nossos avanços e retrocessos no campo que resolvemos estudar e no qual decidimos trabalhar e atuar.

\section{REFERÊNCIAS}

BECKER, Howard S.

Métodos de pesquisa em ciências sociais. 2.ed. São Paulo: Hucitec. 1994.

BECKER, Howard S.

Uma teoria da ação coletiva. 1.ed. Rio de Janeiro:

Zahar Editores. 1977.
BECKER, Howard S.

Outsiders, studies in the sociology of deviance. New York: The Free Press. 1966. 